\title{
Fatores Determinantes da Estrutura de Capital para Empresas Latino-Americanas
}

\author{
Fernanda Finotti Cordeiro Perobelli \\ Rubens Famá
}

\section{Resumo}

Teorias sugerem que empresas selecionam sua estrutura de capital de acordo com atributos teóricos que determinam os vários custos e benefícios associados à emissão de ações ou de dívida. Em uma tentativa de resposta a essa questão, o trabalho desenvolvido por Titman e Wessels (1988) para o mercado americano mostrou-se bastante relevante. Com base nesse estudo e utilizando análise fatorial, procurou-se verificar também para o mercado latino-americano, representado por México, Argentina e Chile, quais seriam os fatores indutores do endividamento das empresas de capital aberto nesses países. Os resultados revelam que os fatores indutores variam de acordo com o país: no México, todos os atributos, à exceção do atributo estrutura dos ativos, mostraram-se relacionados ao grau de endividamento. Na Argentina, apenas o atributo lucratividade mostrou-se relacionado ao grau de endividamento. No Chile, houve relação significativa entre os atributos tamanho, lucratividade e estrutura dos ativos.

Palavras-chaves: emissão de ações; dívida; estrutura de capital; análise fatorial.

\section{Abstract}

Theories suggest that firms select capital structures depending on attributes that determine the various costs and benefits associated with debt and equity financing. With the object of proving this statement, Titman and Wessels (1988) suggested a method that assumes that, although the relevant attributes are not directly observable, we can observe a number of indicator variables that are linear functions of one or more attributes and a random term. In this article, we use a method very similar to this one, using Factor Analysis to extract a measure of correlation between the variable chose as proxy and the attribute of interest. The empirical results showed that, in Mexico, large firms use more long-term debt; profitable firms and growth firms use less short-term and long term debt; firms which have more non-debt tax shields use less short-term debt; but, without explanation, firms which face high volatility of earnings use more short and long term debt. In Argentina, just one relation: profitable firms use less short-term debt. In Chile, small firms use more short-term debt and large firms use more long-term debt; firms that have high levels of tangible assets use more short-term and long-term debt; profitable firms use less long-term (and also short-term) debt.

Key words: equity; debt; capital structure; factor analysis. 


\section{INTRODUÇÃO}

À parte a polêmica em torno da existência de uma estrutura de capital ótima, teorias sugerem que empresas selecionam sua estrutura de capital de acordo com determinados atributos teóricos relevantes, tais como tamanho da empresa, grau de crescimento do negócio, estrutura dos ativos (tangíveis versus intangíveis), singularidade dos produtos oferecidos, lucratividade, volatilidade dos resultados operacionais, entre outros. A relevância desses atributos sobre a decisão de financiamento deriva dos impactos que eles seriam capazes de exercer sobre os custos e benefícios associados à emissão de ações ou de dívida. Dessa forma, não haveria uma estrutura de capital ótima, mas uma estrutura de capital mais apropriada a cada perfil de empresa.

Historicamente, a despeito da importância da decisão de financiamento para a Teoria de Finanças, o consenso acerca da existência de uma estrutura de capital ótima para as empresas nunca foi atingido. Pioneiro nesta questão, Durand (1952, 1959) advogava a existência de tal estrutura. Já Modigliani e Miller (1958, 1959, 1963) defendiam que, observadas certas premissas simplificadoras, a forma como as empresas se financiam seria irrelevante.

Tal polarização, no entanto, é demasiadamente extrema para acomodar as peculiaridades de cada empresa e do cenário onde ela se insere. Deveriam todas as empresas, trabalhando em um cenário onde houvesse isenção de impostos sobre os juros pagos, financiarem-se unicamente com recursos de terceiros, de modo a aproveitar ao máximo os benefícios fiscais do endividamento? Ou, considerando o outro extremo, não havendo impostos ou isenção fiscal, a dívida deixaria de ser instrumento atrativo?

Na prática, não é comum observar-se nenhum desses extremos, tendendo as empresas a comportar-se como se a decisão de financiamento fosse algo bastante relevante. Permanece, portanto, aberta a comprovação dos fatores indutores da estrutura de capital escolhida por cada uma delas.

Em uma tentativa de resposta a essa questão, o trabalho desenvolvido por Titman e Wessels (1988) para o mercado americano mostrou-se bastante relevante. Com base nesse estudo, mas utilizando metodologia diferenciada, o trabalho ora apresentado tem como objetivo central verificar quais seriam os fatores indutores do endividamento em empresas de capital localizadas no México, Argentina e Chile no período compreendido entre 1995 e 2000. 
Sobre o mercado americano, o trabalho de Titman e Wessels (1988) revelou que empresas que apresentam maior grau de singularidade e empresas mais lucrativas apresentam menor propensão ao endividamento tanto de longo quanto de curto prazo; adicionalmente, empresas menores mostraram maior propensão ao endividamento de curto prazo do que empresas maiores.

Para o Brasil, estudo anterior desenvolvido pelos autores (Perobelli e Famá, 2002) revela que o grau de endividamento de curto prazo é negativamente relacionado aos atributos tamanho, crescimento dos ativos e lucratividade das empresas, indicando que empresas maiores, empresas em crescimento e empresas lucrativas são menos propensas a esse tipo de endividamento.

Tomando-se como base esses dois estudos, o presente trabalho tem também como objetivo verificar se resultados similares aos obtidos para o mercado americano (Titman e Wessels, 1988) e para o Brasil (Perobelli e Famá, 2002) são obtidos quando consideradas empresas de capital aberto localizadas em mercados latino-americanos relevantes.

\section{Referencial Teórico}

Considerando-se que nenhuma decisão de investimento deva ser tomada sem que sejam considerados os custos de financiamento, apurados a partir da combinação entre endividamento e capital próprio, é fácil perceber a importância da decisão de financiamento dentro da Teoria de Finanças. Em conjunto com a decisão de investimento e com a decisão de distribuição de resultados, a decisão de quanto empregar de dívida e de capital próprio, seja este alocado por novos acionistas ou gerado internamente, forma um pilar das finanças corporativas modernas.

Sendo os custos de financiamento tão relevantes, é natural que surgissem teóricos preocupados em encontrar uma combinação ótima de endividamento e capital próprio que minimizasse os custos de financiamento da empresa, maximizando, assim, seu valor.

Contrapondo-se aos estudos pioneiros de Durand (1952, 1959), Modigliani e Miller (1958, 1959, 1963) contribuíram sobremaneira para o entendimento dessa questão. Esses autores afirmam que, observadas premissas como ausência de custos de falência, todas as empresas se situarem na mesma classe de risco, ausência de tributação pessoal, ausência de crescimento nos fluxos de caixa das empresas, ausência de assimetria de informação e de custos de agência, a estrutura de capital, ou seja, a forma como as empresas se financiam é irrelevante. 
Por outro lado, havendo dedutibilidade dos juros pagos, o valor de mercado de uma empresa cresceria à medida que ela se endivida, já que o aumento no endividamento implicaria aumento do benefício fiscal apurado. Portanto, na ausência de custos de falência e de tributos sobre a renda pessoal, todas as empresas deveriam financiar-se unicamente com recursos de terceiros.

Mais tarde, Miller (1977) reconheceu que a consideração de tributos pessoais também poderia afetar o valor da empresa. A inclusão da tributação pessoal diminuiria o benefício gerado pela alavancagem no sentido de que, pagando impostos sobre seus ganhos, os credores exigiriam maiores taxas de juros, de forma a compensar a perda para o fisco, aumentando assim o custo do endividamento.

Também os custos de falência deveriam ser considerados na decisão de financiamento: em momento de estresse financeiro, o valor de uma empresa alavancada tenderia a sofrer mais perda do que o de uma empresa não-alavancada, já que, em função do conflito de interesses entre financiadores (acionistas, que muitas vezes desejam ver a reestruturação da empresa, e credores, que tendem a preferir a falência imediata e a partição das garantias), seus fluxos passariam a ser divididos também com terceiras partes (advogados, tribunais etc.). Assim, havendo custos de falência, o custo de capital da empresa não mais seria descendente, à medida que uma empresa se endivida, mas teria a forma de $\mathrm{U}$, revelando que o endividamento apenas traria benefício até o ponto em que ele não comprometesse a saúde financeira da empresa.

A despeito da elegância metodológica dos trabalhos relacionados ao tema, a comprovação da existência de uma estrutura ótima, a ser perseguida pelas empresas, nunca foi atingida. Paralelas a essa discussão, surgiram novas teorias que procuravam explicar a escolha da estrutura de capital pelas empresas a partir de certos atributos. A discussão, portanto, migrou de uma única estrutura ideal para a estrutura mais apropriada a cada perfil de empresa. Alguns trabalhos relevantes nessa linha foram os desenvolvidos por Remmers et al. (1974); Toy et al. (1974); Scott e Martin (1975); Stonehill et al. (1975); Ferri e Jones (1979); DeAngelo e Masulis (1980); Bradley, Jarrel e Kim (1984); Myers e Majluf (1984); Myers (1984); Lumby (1991); Thies e Klock (1992); Balakrishnan e Fox (1993); Allen (1995) e Rajan e Zingales (1995).

De maneira geral, as teorias levantadas até o momento atestam que as empresas escolheriam sua estrutura de capital de acordo com os atributos teóricos abaixo elencados, encontrando-se a lógica subjacente nessa seleção também explicitada.

- Atributo/fator estrutura dos ativos: a idéia geralmente aceita é que empresas com maior volume de ativos tangíveis, que possam ser usados como garantia e 
que reduzam o custo do endividamento, poderiam endividar-se mais (Lumby, 1991; Thies e Klock, 1992; Rajan e Zingales, 1995). Sendo os ativos tangíveis mais facilmente avaliados pelo mercado e mais propensos a relações de troca, então haverá uma relação positiva entre o volume de ativos tangíveis detidos pela empresa e seu nível de endividamento.

\section{- Atributo/fator outros benefícios fiscais que não os gerados pelo} endividamento: a existência de deduções fiscais adicionais (como as advindas da depreciação, por exemplo), competindo pela mesma base de tributação (os lucros), deveria diminuir o apetite das empresas pelo endividamento, se o objetivo deste fosse unicamente reduzir o lucro tributável. Trabalhos como o de Jorge e Armada (1999) para o mercado português discutem essa questão.

- Atributo/fator expectativa de crescimento da empresa: Black e Scholes (1973) sugeriram que o controle das ações de uma empresa alavancada poderia ser visto como opção de compra detida pelos acionistas. Nessa empresa, os acionistas sempre teriam maior incentivo a investir em projetos que oferecessem taxas de retorno mais elevadas, ainda que com pouca probabilidade de sucesso. Assim, caso o projeto se viabilizasse, o acionista embolsaria os altos retornos por ele gerados, pagando aos credores apenas os juros e o principal devidos. Caso o projeto fracassasse, o acionista teria responsabilidade limitada ao pequeno capital investido na empresa, ficando para os credores o prejuízo gerado. Essa tendência é ainda maior em empresas com potencial de crescimento, que têm maior flexibilidade em suas escolhas de investimento ${ }^{(1)}$. Para essas empresas, o custo do endividamento deveria ser maior, desestimulando o endividamento (Toy et al., 1974; Kayo e Famá, 1997).

Atributo/fator singularidade: teorias sugerem que empresas que, ao serem liquidadas, geram alto custo para a sociedade (empresas com alto grau de singularidade), deveriam ser mais conservadoras, evitando o risco de falência e, conseqüentemente, o endividamento. Outra abordagem para a mesma questão sugere que empresas que comercializam produtos muito singulares, cujo valor de mercado residual seja passível de sofrer grandes perdas em um evento de falência, por não se tratar de commodities facilmente intercambiáveis, deveriam enfrentar maiores custos de endividamento.

. Atributo/fator tamanho: alguns autores (Scott e Martin, 1975; Ferri e Jones, 1979; Rajan e Zingales, 1995) atestam que há relação positiva entre tamanho da empresa e grau de endividamento. A justificativa para tal relação é dada pelo fato de que empresas maiores tendem a apresentar maior acessibilidade aos recursos financeiros e maior diversificação de seus negócios, o que resulta em menor probabilidade de dificuldades financeiras e, conseqüentemente, em menores custos de endividamento. 
- Atributo/fator volatilidade: empresas que apresentam menor volatilidade em seus resultados deveriam ser menos propensas a dificuldades financeiras, o que tornaria mais barato o custo do endividamento e, portanto, as tornaria mais propensas à contração de dívidas (Toy et al., 1974; Stonehill et al., 1975; Ferri e Jones, 1979; Bradley, Jarrel e Kim, 1984; Thies e Klock, 1992).

. Atributo/fator lucratividade: segundo a pecking order theory (Myers, 1984), empresas deveriam financiar-se via lucros retidos, endividamento e, em última instância, emissão de ações. Assim, empresas com alta lucratividade deveriam ser menos endividadas, conforme confirmado pelos trabalhos de Eid Jr. (1996) e Soares e Procianoy (2000), realizados no mercado brasileiro.

\section{Metodologia}

Para o teste de algumas das teorias apresentadas, a metodologia empregada neste trabalho baseia-se no trabalho anteriormente desenvolvido por Titman e Wessels (1988) para o mercado americano. Ressalta-se que o método de Modelagem Estrutural Linear, empregado no trabalho de 1988, foi modificado e aplicado por estes autores para o caso brasileiro (Perobelli e Famá, 2002) e também para este caso.

A Modelagem Estrutural Linear, utilizada para o caso americano, é método que conjuga o emprego de Análise Fatorial a uma regressão linear. Esse método assume que, ainda que o pesquisador não possa observar os atributos teóricos relevantes, podem ser observadas variáveis indicativas, que são combinações lineares de um ou mais atributos e um termo de erro e podem, portanto, substituir os atributos não observáveis. O método pode ser definido pelo estabelecimento de um modelo analítico, que consiste em duas partes estimadas conjuntamente: um Modelo de Medida, a partir do qual os atributos não observáveis são relacionados a variáveis observadas e extraído um grau de correlação entre eles, chamado carga fatorial; e um Modelo Estrutural, a partir do qual a variável dependente (endividamento) é escrita como função dos atributos/fatores definidos pelo Modelo de Medida ${ }^{(2)}$. Perobelli e Famá (2002) modificaram tal metodologia aplicando, em substituição ao Modelo de Medida, uma Análise Fatorial prévia às proxies escolhidas para os atributos de interesse e estimando as cargas fatoriais sem qualquer restrição, conforme metodologia exposta em Johnson e Wichern (1992).

Tendo encontrado cargas fatoriais altas entre essas proxies e os atributos teóricos relevantes, o que indica aproximadamente alto grau de correlação entre a 
proxy escolhida e o fator teórico, as proxies, já então testadas pela Análise Fatorial e confirmadas como proxies eficientes para os atributos não observáveis, foram combinadas em um score fatorial, de acordo com a carga fatorial apresentada e o valor da variável original para cada empresa, formando fatores teóricos que foram, posteriormente, utilizados como variáveis independentes em uma regressão cross-sectional para cada país.

Seguindo a proposta de Titman e Wessels (1988) e o trabalho realizado para o Brasil (Perobelli e Famá, 2002), como atributos/fatores determinantes da estrutura de capital das empresas nos diferentes mercados, selecionou-se o seguinte elenco:

. estrutura dos ativos da empresa (colaterais);

. usufruto de outros benefícios fiscais que não os gerados pelo endividamento;

. expectativa de crescimento da empresa;

. grau de singularidade da empresa;

. tamanho da empresa;

. volatilidade de seus resultados operacionais; e

. lucratividade.

Como proxies para cada um desses atributos/fatores, ainda baseando-se no trabalho de Titman e Wessels (1988), foram escolhidas as variáveis listadas no Quadro 1. Como pode ser observado a partir desse quadro, algumas variáveis tais como ativos intangíveis/ativo total, subsídios/ativo total, deduções advindas de compra de equipamentos/ativo total, $\mathrm{P} \& \mathrm{D} /$ vendas, turnover e classificação na indústria, não puderam ser levantadas para os países selecionados por não estarem disponíveis no banco de dados da Economática. Adicionalmente, no caso de empresas mexicanas e chilenas, a variável despesas de vendas/receita líquida não estava disponível. Dessa forma, tais variáveis não foram consideradas por ser a tentativa de obtenção dessas informações caso a caso bastante dificultada pela dimensão da amostra escolhida. Por outro lado, algumas variáveis que não figuravam no estudo de Titman e Wessels (1988), foram incluídas no modelo latino-americano (logaritmo do patrimônio líquido e logaritmo do ativo total, ambas como proxies para o atributo tamanho, seguindo a mesma lógica da proxy logaritmo das vendas), em uma tentativa de aprimoramento do modelo. 


\section{Quadro 1: Atributos Teóricos e Proxies}

\begin{tabular}{|c|c|c|c|c|c|}
\hline Atributo & $\begin{array}{c}\text { Variável testada } \\
\text { (proxy) } \\
\text { Modelo } \\
\text { americano } \\
\text { Titman e } \\
\text { Wessels }(1988)\end{array}$ & $\begin{array}{c}\text { Variável testada } \\
\text { (proxy) } \\
\text { Modelo para o } \\
\text { Brasil } \\
\text { (Perobelli e } \\
\text { Famá, 2002) }\end{array}$ & $\begin{array}{l}\text { Variável testada } \\
\text { (proxy) } \\
\text { Modelo para o } \\
\text { México }\end{array}$ & $\begin{array}{l}\text { Variável testada } \\
\text { (proxy) } \\
\text { Modelo para a } \\
\text { Argentina }\end{array}$ & $\begin{array}{c}\text { Variável testada } \\
\text { (proxy) } \\
\text { Modelo para o } \\
\text { Chile }\end{array}$ \\
\hline $\begin{array}{l}\text { 1.Estrutura dos } \\
\text { ativos } \\
\text { (colaterais) }\end{array}$ & $\begin{array}{l}\text { 1. ativos } \\
\text { intangíveis/ativo } \\
\text { total (INT/TA) } \\
\text { 2. (estoques }+ \\
\text { equipamentos)/ } \\
\text { ativo total } \\
\text { (IGP/TA) } \\
\end{array}$ & \multirow{2}{*}{$\begin{array}{l}\text { 1. (estoque }+ \\
\text { imobilizado)/ativo } \\
\text { total (IGP/TA) } \\
\text { 2. depreciação/ } \\
\text { ativo total (D/TA) }\end{array}$} & $\begin{array}{l}\text { 1. }(\text { estoque }+ \\
\text { imobilizado)/ativo } \\
\text { total (IGP/TA) }\end{array}$ & $\begin{array}{l}\text { 1. }(\text { estoque }+ \\
\text { imobilizado)/ativo } \\
\text { total (IGP/TA) }\end{array}$ & $\begin{array}{l}\text { 1. }(\text { estoque }+ \\
\text { imobilizado)/ativo } \\
\text { total (IGP/TA) }\end{array}$ \\
\hline $\begin{array}{l}\text { 2. Outros } \\
\text { benefícios } \\
\text { fiscais que } \\
\text { não o } \\
\text { endividamento }\end{array}$ & \begin{tabular}{|l|} 
1. subsídios/ativo \\
total (ITC/TA) \\
2. depreciação/ \\
ativo total \\
(D/TA) \\
3. deduções \\
advindas de \\
compra de \\
equipamentos/ \\
ativo total \\
(NDT/AT) \\
\end{tabular} & & $\begin{array}{l}\text { 1. depreciação/ } \\
\text { ativo total (D/TA) } \\
\text { 2. compra de } \\
\text { ativo fixo/ativo } \\
\text { total (CE/TA) }\end{array}$ & $\begin{array}{l}\text { 1. depreciação/ativo } \\
\text { total (D/TA) }\end{array}$ & $\begin{array}{l}\text { 1. depreciação/ } \\
\text { ativo total (D/TA) } \\
\text { 2. (inversões } \\
\text { permanentes }+ \\
\text { compra de ativo } \\
\text { fixo)/ativo total } \\
(\text { CE/TA) }\end{array}$ \\
\hline $\begin{array}{l}\text { 3.Expectativa de } \\
\text { crescimento }\end{array}$ & $\begin{array}{l}\text { 1. gastos de } \\
\text { capital/ativo total } \\
\text { (CE/TA) } \\
\\
\text { 2. crescimento do } \\
\text { ativo total (GTA) } \\
\text { 3. P\&D/vendas } \\
\text { (RD/S) }\end{array}$ & $\begin{array}{l}\text { 1. (aumento do } \\
\text { investimento } \\
\text { permanente }+ \\
\text { compra de ativo } \\
\text { fixo)/ativo total } \\
\text { (CE/TA) } \\
\text { 2. variação média } \\
\text { do ativo total } \\
\text { (GTA) }\end{array}$ & $\begin{array}{l}\text { 1. compra de } \\
\text { ativo fixo/ativo } \\
\text { total (CE/TA) } \\
\\
\text { 2. variação média } \\
\text { do ativo total } \\
\text { (GTA) }\end{array}$ & $\begin{array}{l}\text { 1. (aumento do } \\
\text { investimento } \\
\text { permanente }+ \\
\text { compra de ativo } \\
\text { fixo)/ativo total } \\
\text { (CE/TA) } \\
\text { 2. variação média do } \\
\text { ativo total (GTA) }\end{array}$ & $\begin{array}{l}\text { 1. variação média } \\
\text { do ativo total } \\
\text { (GTA) }\end{array}$ \\
\hline 4. Singularidade & $\begin{array}{l}\text { 1. P\&D/vendas } \\
\text { (RD/S) } \\
\text { 2. despesas de } \\
\text { vendas/vendas } \\
\text { totais }(\mathbf{S E} / \mathbf{S}) \\
\text { 3. turnover }(\mathbf{Q R}) \\
\end{array}$ & $\begin{array}{l}\text { 1. despesas de } \\
\text { venda/receita } \\
\text { líquida }(\mathbf{S E} / \mathbf{S})\end{array}$ & não testada & $\begin{array}{l}\text { 1. despesas de } \\
\text { venda/receita líquida } \\
\text { (SE/S) }\end{array}$ & não testada \\
\hline $\begin{array}{l}\text { 5. Classificação } \\
\text { na indústria }\end{array}$ & $\begin{array}{l}\text { dummy igual a } 1 \\
\text { para empresas de } \\
\text { bens de capital e } \\
\text { igual a zero para } \\
\text { as demais } \\
\text { (IDUM) }\end{array}$ & não testada & não testada & não testada & não testada \\
\hline 6. Tamanho & $\begin{array}{l}\text { 1. logaritmo das } \\
\text { vendas }(\mathbf{L n S}) \\
\text { 2. turnover }(\mathbf{Q R})\end{array}$ & $\begin{array}{l}\text { 1. logaritmo da } \\
\text { receita líquida } \\
\text { (LnS) } \\
\text { 2. logaritmo do } \\
\text { PL médio } \\
\text { (LnBVE) } \\
\text { 3. logaritmo do } \\
\text { ativo total médio } \\
\text { (LnTA) }\end{array}$ & $\begin{array}{l}\text { 1. logaritmo da } \\
\text { receita líquida } \\
\text { (LnS) } \\
\text { 2. logaritmo do } \\
\text { PL médio } \\
\text { (LnBVE) } \\
\text { 3. logaritmo do } \\
\text { ativo total médio } \\
\text { (LnTA) }\end{array}$ & \begin{tabular}{|l|} 
1. logaritmo da \\
receita líquida $(\mathbf{L n S})$ \\
2. logaritmo do PL \\
médio (LnBVE) \\
3. logaritmo do ativo \\
total médio (LnTA)
\end{tabular} & $\begin{array}{l}\text { 1. logaritmo da } \\
\text { receita líquida } \\
\text { (LnS) } \\
\text { 2. logaritmo do } \\
\text { PL médio } \\
\text { (LnBVE) } \\
\text { 3. logaritmo do } \\
\text { ativo total médio } \\
\text { (LnTA) }\end{array}$ \\
\hline
\end{tabular}

Fonte: Titman e Wessels (1988), Perobelli e Famá (2002) e banco de dados da Economática. Nota: os dados da Economática foram trabalhados no software SPSS 8.0. 


\section{Quadro 1: Atributos Teóricos e Proxies (continuação)}

\begin{tabular}{|c|c|c|c|c|c|}
\hline Atributo & \begin{tabular}{|c|} 
Variável testada \\
(proxy) \\
Modelo \\
americano \\
Titman e \\
Wessels (1988) \\
\end{tabular} & $\begin{array}{c}\text { Variável testada } \\
\text { (proxy) } \\
\text { Modelo para o } \\
\text { Brasil } \\
\text { (Perobelli e } \\
\text { Famá, 2002) } \\
\end{array}$ & $\begin{array}{c}\text { Variável testada } \\
\text { (proxy) } \\
\text { Modelo para o } \\
\text { México }\end{array}$ & $\begin{array}{c}\text { Variável testada } \\
\text { (proxy) } \\
\text { Modelo para a } \\
\text { Argentina }\end{array}$ & $\begin{array}{c}\text { Variável testada } \\
\text { (proxy) } \\
\text { Modelo para o } \\
\text { Chile }\end{array}$ \\
\hline 7. Volatilidade & $\begin{array}{l}\text { desvio-padrão da } \\
\text { variação no } \\
\text { resultado } \\
\text { operacional } \\
\text { (SIGOI) }\end{array}$ & $\begin{array}{l}\text { desvio-padrão da } \\
\text { variação do } \\
\text { resultado } \\
\text { operacional } \\
\text { próprio (SIGOI) }\end{array}$ & $\begin{array}{l}\text { desvio-padrão da } \\
\text { variação do } \\
\text { resultado } \\
\text { operacional } \\
\text { próprio (SIGOI) } \\
\end{array}$ & $\begin{array}{l}\text { desvio-padrão da } \\
\text { variação do } \\
\text { resultado } \\
\text { operacional próprio } \\
\text { (SIGOI) }\end{array}$ & $\begin{array}{l}\text { desvio-padrão da } \\
\text { variação do } \\
\text { resultado } \\
\text { operacional } \\
\text { próprio (SIGOI) } \\
\end{array}$ \\
\hline 8. Lucratividade & $\begin{array}{l}\text { 1. resultado } \\
\text { operacional/ } \\
\text { vendas }(\mathbf{O I} / \mathbf{S}) \\
\text { 2. resultado } \\
\text { operacional/ativo } \\
\text { total }(\mathbf{O I} / \mathbf{T A})\end{array}$ & $\begin{array}{l}\text { 1. resultado } \\
\text { operacional } \\
\text { próprio/ativo total } \\
\text { (OI/TA) }\end{array}$ & $\begin{array}{l}\text { 1. resultado } \\
\text { operacional } \\
\text { próprio/receita } \\
\text { líquida }(\mathbf{O I} / \mathbf{S}) \\
\text { 2. resultado } \\
\text { operacional } \\
\text { próprio/ativo total } \\
\text { (OI/TA) }\end{array}$ & $\begin{array}{l}\text { 1. resultado } \\
\text { operacional } \\
\text { próprio/receita } \\
\text { líquida }(\mathbf{O I} / \mathbf{S}) \\
\text { 2. resultado } \\
\text { operacional } \\
\text { próprio/ativo total } \\
\text { (OI/TA) }\end{array}$ & $\begin{array}{l}\text { 1. resultado } \\
\text { operacional } \\
\text { próprio/ativo total } \\
\text { (OI/TA) }\end{array}$ \\
\hline 9. Margem & & $\begin{array}{l}\text { 1. resultado } \\
\text { operacional } \\
\text { próprio/receita } \\
\text { líquida }(\mathbf{O I} / \mathbf{S})\end{array}$ & & & $\begin{array}{l}\text { 1. resultado } \\
\text { operacional } \\
\text { próprio/receita } \\
\text { líquida }(\mathbf{O I} / \mathbf{S})\end{array}$ \\
\hline
\end{tabular}

Fonte: Titman e Wessels (1988), Perobelli e Famá (2002) e banco de dados da Economática. Nota: os dados da Economática foram trabalhados no software SPSS 8.0.

Tais variáveis, apuradas por meio do banco de dados da Economática e extraídas dos Balanços Patrimoniais, Demonstrações de Resultado e Demonstração de Origem e Aplicação dos Recursos apresentados pelas empresas no encerramento do exercício, foram observadas no período de 1995 a 2000 e extraídas as médias no período. No caso da Argentina e Chile, os dados levantados foram os não-consolidados. Já o México apenas apresentou demonstrações consolidadas. Adicionalmente, todos os valores foram expressos em dólares de final de período.

A amostra, selecionada de acordo com a disponibilidade de informações no banco de dados utilizado, contou com 119 empresas de capital aberto localizadas no México, 57 na Argentina e 103 no Chile. A estatística descritiva referente à amostra considerada encontra-se disposta na Tabela 1.

Para a estimação da regressão, os fatores teóricos encontrados a partir da Análise Fatorial (scores fatoriais) foram considerados como variáveis independentes e o grau de endividamento de longo e curto prazo, padronizado em relação ao valor contábil e apurado conforme exposto abaixo, como variável dependente.

. LT/BVE - grau de endividamento de longo prazo: somatório das médias das contas do Balanço Patrimonial 'Financiamento de Longo Prazo' e 'Debêntures de Longo Prazo', dividido pela média da conta 'Patrimônio Líquido'.

. ST/BVE - grau de endividamento de curto prazo: somatório das médias das contas do Balanço Patrimonial ‘Financiamento de Curto Prazo’ e ‘Debêntures de Curto Prazo', dividido pela média da conta 'Patrimônio Líquido'. 
Infelizmente, tal como esclarece Titman e Wessels (1988) em seu trabalho, as teorias subjacentes nesses testes não indicam a forma de relação entre os atributos e o grau de endividamento. Dessa forma, a exemplo do trabalho citado, o presente estudo também empregou um modelo no qual tal relação é linear (regressão linear múltipla).

\section{Tabela 1: Estatísticas Descritivas}

\begin{tabular}{|l|c|c|c|c|c|}
\hline \multicolumn{7}{|c|}{ Argentina } \\
\hline \hline \multicolumn{1}{|c|}{ Variáveis } & \# de casos & Valor mínimo & Valor máximo & Média & Desvio-padrão \\
\hline ST/BVE (\% do PL) & 57 & 0,0 & 368,5 & 33,12 & 52,74 \\
\hline LT/BVE (\% do PL) & 57 & 0,0 & 232,7 & 29,7 & 40,0 \\
\hline IGP/TA (\% do ativo total) & 57 & 6,1 & 91,6 & 55,6 & 21,0 \\
\hline D/TA (\% do ativo total) & 57 & 0,5 & 12,2 & 3,8 & 2,3 \\
\hline CE/TA (\% do ativo total) & 57 & 1,1 & 28,9 & 8,1 & 5,8 \\
\hline OI/TA (\% do ativo total) & 57 & $-8,9$ & 24,4 & 4,9 & 5,7 \\
\hline OI/S (\% da receita líquida) & 57 & $-23,3$ & 68,4 & 10,8 & 14,5 \\
\hline SE/S (\% da receita líquida) & 57 & 0,0 & 31,6 & 10,4 & 8,6 \\
\hline LnS (logaritmo) & 57 & 8,8 & 15,6 & 11,6 & 1,5 \\
\hline LnBVE (logaritmo) & 57 & 9,2 & 15,8 & 11,8 & 1,5 \\
\hline LnTA (logaritmo) & 57 & 9,5 & 16,2 & 12,4 & 1,5 \\
\hline SIGOI (em desvio-padrão) & 57 & 3,8 & 5395,6 & 330,2 & 826,6 \\
\hline GTA (variação \%) & 57 & $-24,6$ & 141,9 & 8,2 & 21,4 \\
\hline
\end{tabular}

\begin{tabular}{|c|c|c|c|c|c|}
\hline \multicolumn{6}{|c|}{ México } \\
\hline Variáveis & \# de casos & Valor mínimo & Valor máximo & Média & $\begin{array}{l}\text { Desvio- } \\
\text { padrão }\end{array}$ \\
\hline ST/BVE (\% do PL) & 119 & 0,0 & 1369,4 & 47,7 & 179,5 \\
\hline LT/BVE (\% do PL) & 119 & 0,0 & 1025,5 & 50,9 & 132,4 \\
\hline $\begin{array}{l}\text { IGP/TA (\% do ativo } \\
\text { total) }\end{array}$ & 119 & 10,2 & 97,7 & 62,7 & 17,3 \\
\hline $\begin{array}{l}\text { D/TA (\% do ativo } \\
\text { total) }\end{array}$ & 119 & 0,7 & 12,1 & 3,5 & 1,9 \\
\hline $\begin{array}{l}\text { CE/TA (\% do ativo } \\
\text { total) }\end{array}$ & 119 & $-2,7$ & 20,7 & 4,8 & 3,5 \\
\hline $\begin{array}{l}\text { OI/TA (\% do ativo } \\
\text { total) }\end{array}$ & 119 & $-12,5$ & 20,9 & 7,9 & 6,0 \\
\hline $\begin{array}{l}\text { OI/S (\% da receita } \\
\text { líquida) }\end{array}$ & 119 & $-94,7$ & 43,9 & 10,3 & 14,3 \\
\hline LnS (logaritmo) & 119 & 6,1 & 15,9 & 12,4 & 1,7 \\
\hline LnBVE (logaritmo) & 119 & 8,5 & 16,1 & 12,1 & 1,7 \\
\hline LnTA (logaritmo) & 119 & 9,0 & 16,6 & 12,8 & 1,7 \\
\hline $\begin{array}{l}\text { SIGOI (em desvio- } \\
\text { padrão) }\end{array}$ & 119 & 5,6 & 9737,1 & 361,2 & 1355,2 \\
\hline GTA (variação \%) & 119 & $-21,2$ & 142,6 & 19,3 & 23,3 \\
\hline
\end{tabular}

Fonte: banco de dados da Economática. 
Tabela 1: Estatísticas Descritivas (continuação)

\begin{tabular}{|l|c|c|c|c|c|}
\hline \multicolumn{1}{|c|}{ Variáveis } & \# de casos & Valor mínimo & Valor máximo & Média & $\begin{array}{c}\text { Desvio- } \\
\text { padrão }\end{array}$ \\
\hline \hline ST/BVE (\% do PL) & 103 & 0,0 & 39,0 & 5,9 & 6,0 \\
\hline LT/BVE (\% do PL) & 103 & 0,0 & 46,1 & 9,5 & 10,2 \\
\hline $\begin{array}{l}\text { IGP/TA (\% do ativo } \\
\text { total) }\end{array}$ & 103 & 0,0 & 96,2 & 41,4 & 27,7 \\
\hline $\begin{array}{l}\text { D/TA (\% do ativo } \\
\text { total) }\end{array}$ & 103 & 0,0 & 476,4 & 7,1 & 46,7 \\
\hline $\begin{array}{l}\text { CE/TA (\% do ativo } \\
\text { total) }\end{array}$ & 103 & $-1,1$ & 345,1 & 7,5 & 33,8 \\
\hline $\begin{array}{l}\text { OI/TA (\% do ativo } \\
\text { total) }\end{array}$ & 103 & $-3,5$ & 41,8 & 7,1 & 7,7 \\
\hline $\begin{array}{l}\text { OI/S (\% da receita } \\
\text { líquida) }\end{array}$ & 103 & $-3882,6$ & 92,5 & $-40,3$ & 400,2 \\
\hline LnS (logaritmo) & 103 & 3,3 & 14,3 & 10,6 & 1,9 \\
\hline LnBVE (logaritmo) & 103 & 9,1 & 15,2 & 11,7 & 1,3 \\
\hline LnTA (logaritmo) & 103 & 9,7 & 15,4 & 12,1 & 1,3 \\
\hline $\begin{array}{l}\text { SIGOI (em desvio- } \\
\text { padrão) }\end{array}$ & 103 & 4,2 & 6372,4 & 203,5 & 661,8 \\
\hline GTA (variação \%) & 103 & $-66,2$ & 41,2 & 5,7 & 12,5 \\
\hline
\end{tabular}

Fonte: banco de dados da Economática.

\section{Resultados}

A adaptação do modelo proposto por Titman e Wessels (1988) para empresas de capital aberto mexicanas, argentinas e chilenas ora apresentada tem dois objetivos. O central é verificar os fatores indutores de endividamento para essas empresas; como objetivo secundário, optou-se por verificar a convergência entre os resultados dos estudos realizados nos diferentes mercados: americano, brasileiro, mexicano, argentino e chileno.

\section{Resultados da Análise Fatorial: Extração e Avaliação dos Atributos/Fatores Teóricos a Serem Utilizados como Variáveis Independentes na Regressão}

Para atingir os objetivos mencionados, apresentam-se as tabelas a seguir, referentes à primeira parte da metodologia: estimação das cargas fatoriais e verificação da aderência das proxies escolhidas aos atributos teóricos não observáveis. Ressalta-se que as cargas fatoriais encontradas por Titman e Wessels (1988) em seu trabalho foram estimadas com restrição (estabelecendo a priori algumas 
cargas fatoriais como iguais a zero ou um), conforme mostra a Tabela 2, enquanto as cargas fatoriais para os casos latino-americanos foram estimadas por Análise Fatorial sem restrições, conforme mostram as Tabelas 3 (Brasil), 4 (México), 5 (Argentina) e 6 (Chile).

É importante esclarecer que, ao estimar as cargas fatoriais sem qualquer restrição neste estudo, os autores tinham como objetivo elevar a confiabilidade da aderência das proxies aos atributos teóricos de interesse. Note que Titman e Wessels (1988) estabeleceram a priori a relação entre a proxy desvio-padrão da variação do resultado operacional (SIGOI) e o atributo/fator volatilidade como sendo igual a 1. Já nos estudos realizados para os mercados latino-americanos, com a estimação sem restrição, as cargas fatoriais encontradas foram bem próximas deste valor: 0,995 (Brasil), 0,987 (México), 0,974 (Argentina) e 0,994 (Chile), sem que fosse necessária a imposição de tal relação ser igual a 1 a priori.

Tabela 2: Modelo de Titman e Wessels

Modelo de Medida com Restrição: Cargas Fatorias para as Variáveis Independentes (Atributos/Fatores)

\begin{tabular}{|c|c|c|c|c|c|c|c|c|}
\hline \multirow[b]{2}{*}{ Variáveis } & \multicolumn{8}{|c|}{ Atributos } \\
\hline & $\begin{array}{c}\text { E1 } \\
\text { (Crescimento) }\end{array}$ & $\begin{array}{c}\text { E2 } \\
\text { (Singularidade) }\end{array}$ & $\begin{array}{c}\text { E3 } \\
\text { (Outros } \\
\text { Benefícios) } \\
\end{array}$ & $\begin{array}{c}\text { E4 } \\
\text { (Colaterais) }\end{array}$ & $\begin{array}{c}\text { E5 } \\
\text { (Tamanho) }\end{array}$ & $\begin{array}{c}\text { E6 } \\
\text { (Lucratividade) }\end{array}$ & $\begin{array}{c}\text { E7 } \\
\text { (Volatilidade) }\end{array}$ & $\begin{array}{c}\text { E8 } \\
\text { (Classificação } \\
\text { na Indústria) }\end{array}$ \\
\hline NDT/TA & 0 & 0 & 0,779 & 0 & 0 & 0 & 0 & 0 \\
\hline ITC/DA & 0 & 0 & 0,606 & 0 & 0 & 0 & 0 & 0 \\
\hline $\mathrm{D} / \mathrm{TA}$ & 0 & 0 & 0,848 & 0 & 0 & 0 & 0 & 0 \\
\hline $\mathrm{RD} / \mathrm{S}$ & 0,246 & 0,781 & 0 & 0 & 0 & 0 & 0 & 0 \\
\hline $\mathrm{SE} / \mathrm{S}$ & 0 & 0,681 & 0 & 0 & 0 & 0 & 0 & 0 \\
\hline CE/TA & 0,951 & 0 & 0 & 0 & 0 & 0 & 0 & 0 \\
\hline INT/TA & 0 & 0 & 0 & $-0,331$ & 0 & 0 & 0 & 0 \\
\hline IGP/TA & 0 & 0 & 0 & 1,180 & 0 & 0 & 0 & 0 \\
\hline $\operatorname{LnS}$ & 0 & 0 & 0 & 0 & 0,938 & 0 & 0 & 0 \\
\hline GTA & 0,471 & 0 & 0 & 0 & 0 & 0 & 0 & 0 \\
\hline QR & 0 & $-0,228$ & 0 & 0 & $-0,273$ & 0 & 0 & 0 \\
\hline OI/TA & 0 & 0 & 0 & 0 & 0 & 0,641 & 0 & 0 \\
\hline $\mathrm{OI} / \mathrm{S}$ & 0 & 0 & 0 & 0 & 0 & 0,998 & 0 & 0 \\
\hline SIGOI & 0 & 0 & 0 & 0 & 0 & 0 & 1 & 0 \\
\hline IDUM & 0 & 0 & 0 & 0 & 0 & 0 & 0 & 1 \\
\hline
\end{tabular}

Fonte: Titman e Wessels (1988). 
Tabela 3: Modelo para o Brasil

Modelo de Medida sem Restrição: Cargas Fatorias para as Variáveis Independentes (Atributos/Fatores)

\begin{tabular}{|c|c|c|c|c|c|c|c|}
\hline \multirow[b]{2}{*}{ Variáveis } & \multicolumn{7}{|c|}{ Atributos $(*)$} \\
\hline & $\begin{array}{c}\text { E1 } \\
\text { (Tamanho) }\end{array}$ & $\begin{array}{c}\text { E2 } \\
\text { (Colaterais) }\end{array}$ & $\begin{array}{c}\text { E3 } \\
\text { (Crescimento) }\end{array}$ & $\begin{array}{c}\text { E4 } \\
\text { (Singularidade) }\end{array}$ & $\begin{array}{c}\text { E5 } \\
\text { (Margem) }\end{array}$ & $\begin{array}{c}\text { E6 } \\
\text { (Lucratividade) }\end{array}$ & $\begin{array}{c}\text { E7 } \\
\text { (Volatilidade) }\end{array}$ \\
\hline $\mathrm{D} / \mathrm{TA}$ & & 0,899 & & & & & \\
\hline SE/S & & & & 0,977 & & & \\
\hline CE/TA & & & 0,919 & & & & \\
\hline IGP/TA & & 0,812 & & & & & \\
\hline LnS & 0,873 & & & & & & \\
\hline LnBVE & 0,941 & & & & & & \\
\hline LnTA & 0,976 & & & & & & \\
\hline GTA & & & 0,707 & & & & \\
\hline $\mathrm{OI} / \mathrm{TA}$ & & & & & & 0,884 & \\
\hline $\mathrm{OI} / \mathrm{S}$ & & & & & 0,976 & & \\
\hline SIGOI & & & & & & & 0,995 \\
\hline
\end{tabular}

Fonte: Perobelli e Famá (2002).

(*) Todas as demais cargas fatoriais foram inferiores a $0.40 \mathrm{e}$, portanto, suprimidas pelo software SPSS 8.0.

Tabela 4: Modelo para o México

Modelo de Medida sem Restrição: Cargas Fatorias para as Variáveis Independentes (Atributos/Fatores)

\begin{tabular}{|c|c|c|c|c|c|c|}
\hline \multirow[b]{2}{*}{ Variáveis } & \multicolumn{6}{|c|}{ Atributos $(*)$} \\
\hline & $\begin{array}{c}\text { E1 } \\
\text { (Tamanho) }\end{array}$ & $\begin{array}{c}\text { E2 } \\
\text { (Lucratividade) }\end{array}$ & $\begin{array}{c}\text { E3 } \\
\text { (Outros } \\
\text { benefícios) }\end{array}$ & $\begin{array}{c}\text { E4 } \\
\text { (Crescimento) }\end{array}$ & $\begin{array}{c}\text { E5 } \\
\text { (Colaterais) }\end{array}$ & $\begin{array}{c}\text { E6 } \\
\text { (Volatilidade) }\end{array}$ \\
\hline D/TA & & & 0,920 & & & \\
\hline $\mathrm{CE} / \mathrm{TA}$ & & & 0,683 & 0,520 & & \\
\hline IGP/TA & & & & & 0,962 & \\
\hline $\operatorname{LnS}$ & 0,944 & & & & & \\
\hline LnBVE & 0,985 & & & & & \\
\hline LnTA & 0,952 & & & & & \\
\hline GTA & & & & 0,901 & & \\
\hline OI/TA & & 0,908 & & & & \\
\hline $\mathrm{OI} / \mathrm{S}$ & & 0,872 & & & & \\
\hline SIGOI & & & & & & 0,987 \\
\hline
\end{tabular}

Fonte: banco de dados da Economática.

$\left(^{*}\right)$ Todas as demais cargas fatoriais foram inferiores a 0.40 e, portanto, suprimidas pelo software SPSS 8.0. 
Tabela 5: Modelo para a Argentina

Modelo de Medida sem Restrição: Cargas Fatorias para as Variáveis Independentes (Atributos/Fatores)

\begin{tabular}{|c|c|c|c|c|c|c|c|}
\hline \multirow[b]{2}{*}{ Variáveis } & \multicolumn{7}{|c|}{ Atributos $(*)$} \\
\hline & $\begin{array}{c}\text { E1 } \\
\text { (Tamanho) }\end{array}$ & $\begin{array}{c}\text { E2 } \\
\text { (Crescimento) }\end{array}$ & $\begin{array}{c}\text { E3 } \\
\text { (Lucratividade) }\end{array}$ & $\begin{array}{c}\text { E4 } \\
\text { (Outros } \\
\text { benefícios) }\end{array}$ & $\begin{array}{c}\text { E5 } \\
\text { (Singularidade) }\end{array}$ & $\begin{array}{c}\text { E6 } \\
\text { (Volatilidade) }\end{array}$ & $\begin{array}{c}\text { E7 } \\
\text { (Colaterais) }\end{array}$ \\
\hline D/TA & & & & 0,940 & & & \\
\hline $\mathrm{SE} / \mathrm{S}$ & & & & & 0,974 & & \\
\hline CE/TA & & 0,807 & & & & & \\
\hline IGP/TA & & & & & & & 0,948 \\
\hline $\operatorname{LnS}$ & 0,853 & & & & & & \\
\hline LnBVE & 0,945 & & & & & & \\
\hline LnTA & 0,953 & & & & & & \\
\hline GTA & & 0,931 & & & & & \\
\hline $\mathrm{OI} / \mathrm{TA}$ & & & 0,898 & & & & \\
\hline $\mathrm{OI} / \mathrm{S}$ & & & 0,788 & & & & \\
\hline SIGOI & & & & & & 0,974 & \\
\hline
\end{tabular}

Fonte: banco de dados da Economática.

(*) Todas as demais cargas fatoriais foram inferiores a 0.40 e, portanto, suprimidas pelo software SPSS 8.0.

Tabela 6: Modelo para o Chile

Modelo de Medida sem Restrição: Cargas Fatorias para as Variáveis Independentes (Atributos/Fatores)

\begin{tabular}{|c|c|c|c|c|c|c|c|}
\hline \multirow[b]{2}{*}{ Variáveis } & \multicolumn{7}{|c|}{ Atributos $(*)$} \\
\hline & $\begin{array}{c}\text { E1 } \\
\text { (Tamanho) }\end{array}$ & $\begin{array}{c}\text { E2 } \\
\text { (Outros } \\
\text { benefícios) }\end{array}$ & $\begin{array}{c}\text { E3 } \\
\text { (Margem) }\end{array}$ & $\begin{array}{c}\mathrm{E} 4 \\
\text { (Colaterais) }\end{array}$ & $\begin{array}{c}\text { E5 } \\
\text { (Lucratividade) }\end{array}$ & $\begin{array}{c}\text { E6 } \\
\text { (Volatilidade) }\end{array}$ & $\begin{array}{c}\text { E7 } \\
\text { (Crescimento) }\end{array}$ \\
\hline D/TA & & 0,997 & & & & & \\
\hline CE/TA & & 0,996 & & & & & \\
\hline IGP/TA & & & & 0,965 & & & \\
\hline $\operatorname{LnS}$ & 0,554 & & & & & & \\
\hline LnBVE & 0,952 & & & & & & \\
\hline LnTA & 0,961 & & & & & & \\
\hline GTA & & & & & & & 0,954 \\
\hline OI/TA & & & & & 0,931 & & \\
\hline $\mathrm{OI} / \mathrm{S}$ & & & 0,983 & & & & \\
\hline SIGOI & & & & & & 0,994 & \\
\hline
\end{tabular}

Fonte: banco de dados da Economática.

(*) Todas as demais cargas fatoriais foram inferiores a 0.40 e, portanto, suprimidas pelo software SPSS 8.0. 
A Análise Fatorial para a Argentina mostrou-se idêntica ao caso americano. Já para o México, uma única divergência foi encontrada em relação ao trabalho de Titman e Wessels (1988): a proxy gastos de capital/ativos totais (CE/TA) no caso mexicano mostrou-se relacionada não apenas ao atributo/fator crescimento dos ativos, mas também ao atributo/fator outros benefícios fiscais que não os gerados pelo endividamento, indicando haver benefícios fiscais decorrentes da aquisição de ativos fixos no México. O mesmo aconteceu no Chile, onde a proxy mostrou-se correlacionada unicamente a este último fator. Autores como Bradley, Jarrel e Kim (1984) e Balakrishnan e Fox (1993), relacionaram essas outras vantagens fiscais com a composição dos ativos da empresa.

Já em relação ao Brasil, todos os outros países apresentaram divergência em relação à proxy depreciação/ativo total. Essa proxy, para o Brasil, mostrou-se não correlacionada ao atributo/fator outros benefícios fiscais que não os gerados pelo endividamento, mas bastante correlacionada ao atributo/fator estrutura dos ativos (Perobelli e Famá, 2002). Essa é uma conclusão bastante lógica para o caso brasileiro, já que a depreciação provisionada pelas empresas brasileiras é função direta de seus ativos imobilizados, conta que, por sua vez, integra a proxy escolhida para o atributo/fator estrutura dos ativos.

Uma justificativa para tal divergência seria o fato de a proxy depreciação/ativo total não manter o mesmo grau de relação com a proxy imobilizado+estoques/ ativo total apresentado no Brasil e nos demais países latino-americanos. A não ocorrência de tal relação, conforme explicitada nos Gráficos 2, 3 e 4, pode ser influenciada pelo volume de estoques (não sujeitos a depreciação) em relação ao ativo imobilizado na amostra selecionada para esses países.

Gráfico 1: Brasil

Relação entre Depreciação e Ativo Imobilizado+Estoques

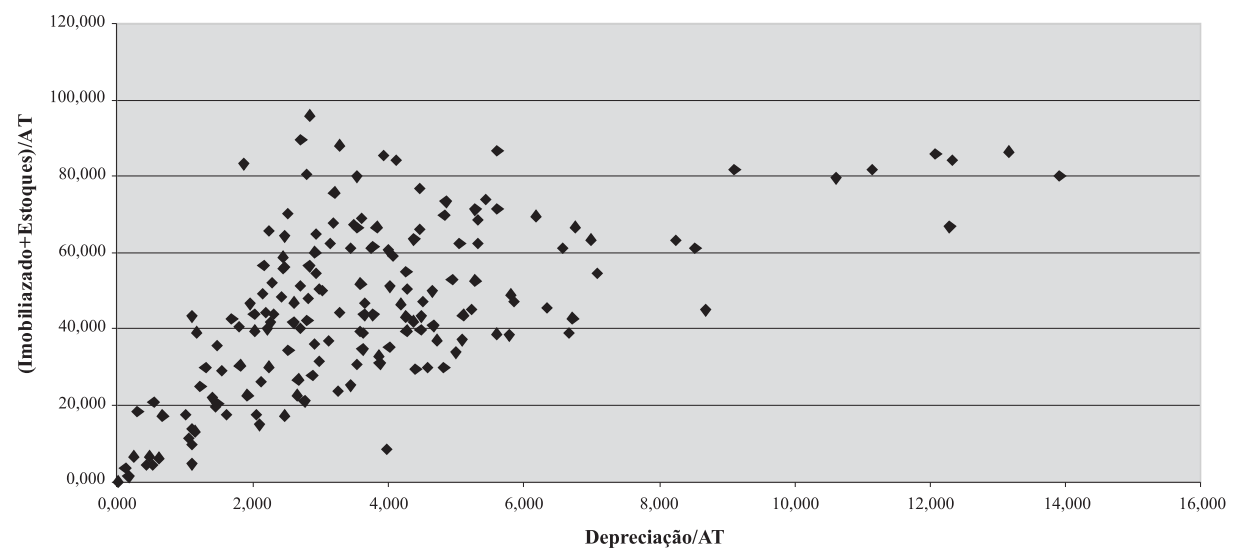

Fonte: banco de dados da Economática. 


\section{Gráfico 2: México}

\section{Relação Depreciação x Ativo Imobilizado+Estoques}

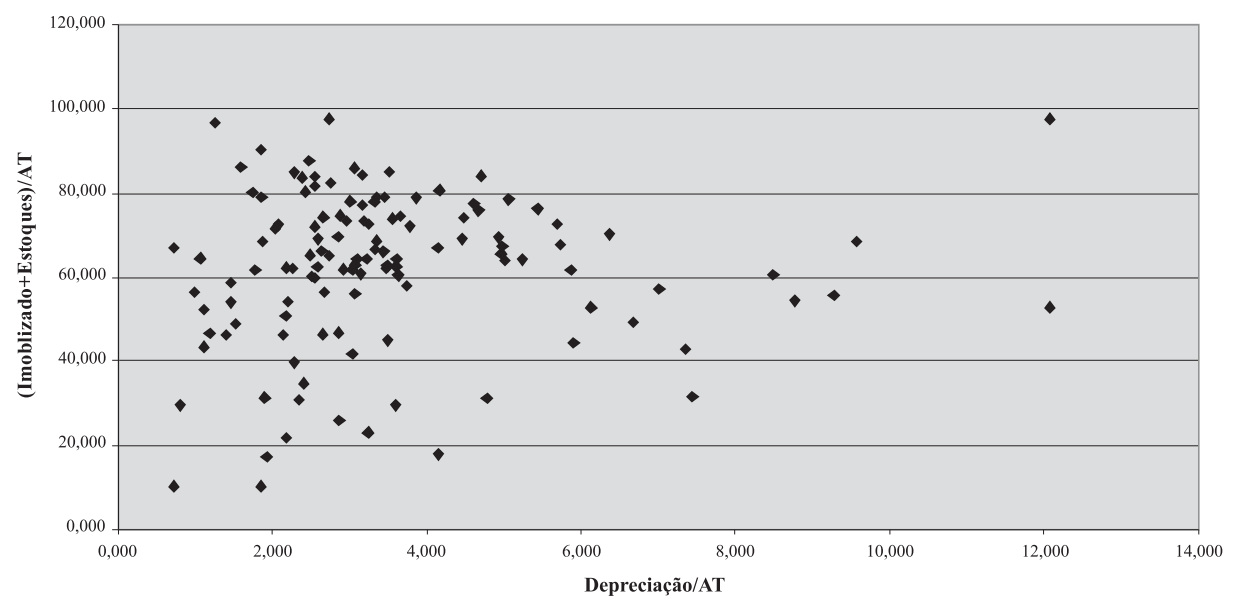

Fonte: banco de dados da Economática.

\section{Gráfico 3: Argentina}

Relação Depreciação x Ativo Imobilizado+Estoques

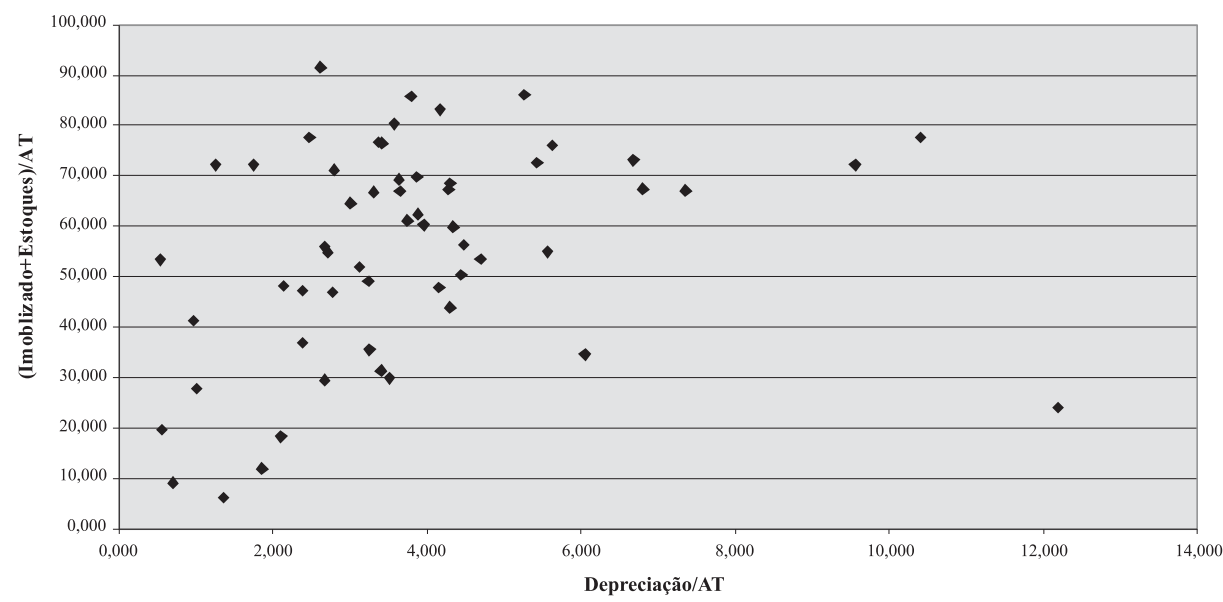

Fonte: banco de dados da Economática. 


\section{Gráfico 4: Chile}

\section{Relação Depreciação x Ativo Imobilizado+Estoques}

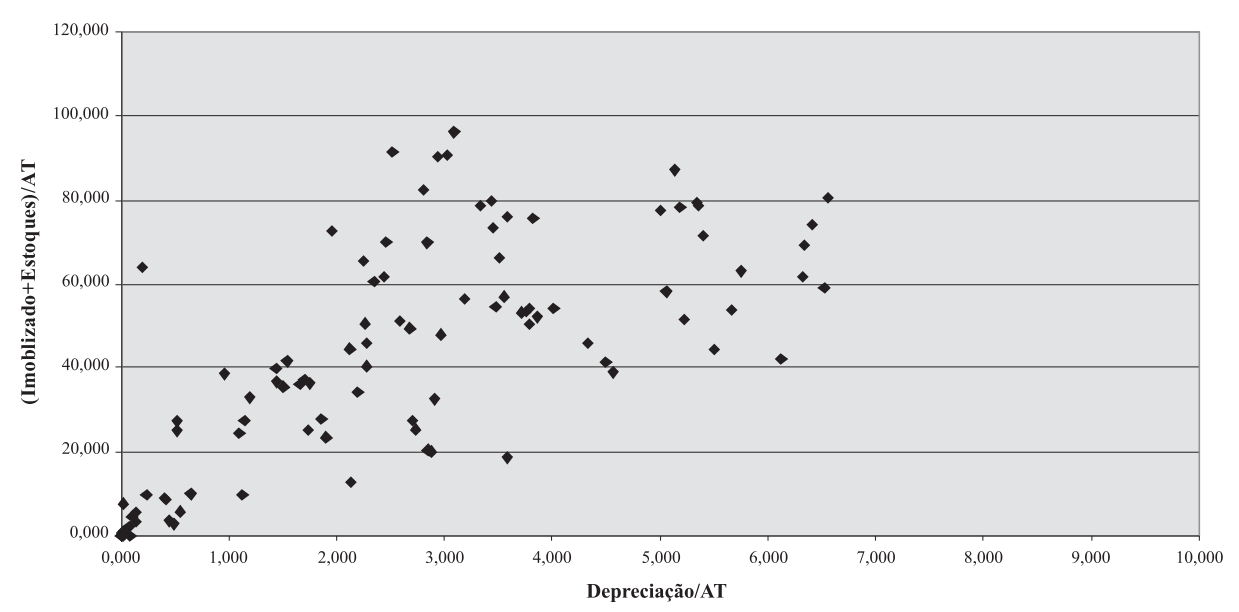

Fonte: banco de dados da Economática.

Uma segunda divergência relevante entre todos os casos analisados foi a verificada na estimação do atributo lucratividade. Para o caso brasileiro e chileno, diferente dos casos americano, argentino e mexicano, os resultados da Análise Fatorial revelaram que as proxies resultado operacional/receita líquida e resultado operacional/ativo total não são relacionadas ao mesmo atributo. Tal divergência poderia ser atribuída ao fato de a primeira proxy (resultado operacional/receita líquida) estabelecer a margem obtida pela empresa, enquanto a segunda (resultado operacional/ativo total) definir a lucratividade obtida pela empresa, que é uma função não apenas da margem praticada, mas também do giro do ativo e, portanto, embutir o componente giro:

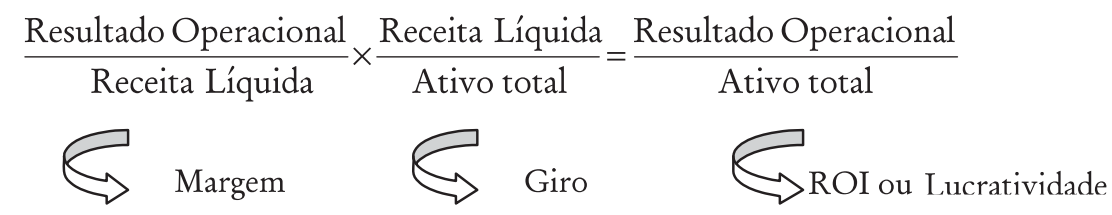

Em uma tentativa de entendimento dessa divergência, apurou-se para os casos latino-americanos o grau de relação entre margem (OI/S) e lucratividade (OI/ TA) por meio do cômputo do percentual da lucratividade mediana relacionado à margem mediana para cada país.

Nos países latino-americanos onde, de acordo com a Análise Fatorial, essas proxies se mostraram correlacionadas (México e Argentina), esperava-se que grande parcela da margem fosse convertida em lucratividade, ou seja, que o 
cociente das medianas fosse elevado. Pelo mesmo raciocínio, nos países onde as proxies não se mostraram correlacionadas (Brasil e Chile), esperava-se um cociente baixo, indicando que margens altas não são necessariamente convertidas em altas lucratividades, basicamente pela influência do componente giro que, nestes casos, seria baixo. O resultado desta análise encontra-se sumariado na Tabela 7.

Tabela 7: Relação entre Lucratividade (OI/AT) e Margem (OI/S)

\begin{tabular}{lrrr}
\hline \hline País & $\begin{array}{c}\text { Mediana da Margem } \\
(\mathrm{OI} / \mathrm{S})\end{array}$ & $\begin{array}{c}\text { Mediana da Lucratividade } \\
\text { (OI/TA) }\end{array}$ & $\begin{array}{c}\text { \% da Margem convertida } \\
\text { em Lucratividade }\end{array}$ \\
\hline Brasil & 7,05 & 3,78 & $\mathbf{5 3 , 6 \%}$ \\
México & 9,86 & 7,90 & $\mathbf{8 0 , 1 \%}$ \\
Argentina & 7,15 & 3,85 & $\mathbf{5 3 , 8 \%}$ \\
Chile & 15,39 & 5,41 & $\mathbf{3 5 , 2 \%}$ \\
\hline
\end{tabular}

Fonte: banco de dados da Economática.

Conforme revela a Tabela 7, para os casos argentino e mexicano, realmente $53,8 \%$ e $80,1 \%$ respectivamente da margem mediana praticada nesses países é convertida em lucratividade. Para o caso chileno, no entanto, apenas $35,2 \%$ da margem mediana obtida pelas empresas transforma-se em lucratividade efetiva, o que sinaliza um baixo giro nas empresas componentes da amostra. O cociente para o Brasil, entretanto, não apresentou comportamento compatível com os resultados da Análise Fatorial anteriormente encontrados no trabalho de Perobelli e Famá (2002).

A investigação dessa discrepância levou à análise de potenciais outliers que pudessem estar distorcendo a análise, não só em relação às duas proxies em exame (OI/TA e OI/S), mas também em relação a todas as demais.

Considerando-se o quadro de estatísticas descritivas da amostra brasileira, apresentado por Perobelli e Famá (2002), alguns valores discrepantes podem ser apontados. São eles: grau de endividamento de longo prazo (LT/BVE) da empresa Varig $(1.058,221)$; volatilidade dos resultados operacionais (SIGOI) das empresas Aracruz $(31.842,89)$, Cia. Hering $(19.392,58)$ e margem operacional (OI/ S) da empresa Supergasbrás $(-914,827)$. Para analisar a potencial influência desses valores extremos sobre a análise, foi realizada nova Análise Fatorial, desconsiderando-se tais valores. O resultado dessa análise encontra-se na Tabela 8 . 
Tabela 8: Modelo para o Brasil sem Outliers

Modelo de Medida sem Restrição: Cargas Fatoriais para as Variáveis Independentes (Atributos/Fatores)

\begin{tabular}{|c|c|c|c|c|c|c|}
\hline \multirow[b]{2}{*}{ Variáveis } & \multicolumn{6}{|c|}{ Atributos $(*)$} \\
\hline & $\begin{array}{c}\text { E1 } \\
\text { (Tamanho) }\end{array}$ & $\begin{array}{c}\mathrm{E} 2 \\
\text { (Colaterais) }\end{array}$ & $\begin{array}{c}\text { E3 } \\
\text { (Crescimento) }\end{array}$ & $\begin{array}{c}\text { E4 } \\
\text { (Singularidade) }\end{array}$ & $\begin{array}{c}\text { E5 } \\
\text { (Lucratividade) }\end{array}$ & $\begin{array}{c}\text { E6 } \\
\text { (Volatilidade) }\end{array}$ \\
\hline $\mathrm{D} / \mathrm{TA}$ & & 0,896 & & & & \\
\hline $\mathrm{SE} / \mathrm{S}$ & & & & 0,951 & & \\
\hline CE/TA & & & 0,881 & & & \\
\hline IGP/TA & & 0,826 & & & & \\
\hline $\mathrm{LnS}$ & 0,904 & & & & & \\
\hline LnBVE & 0,904 & & & & & \\
\hline LnTA & 0,954 & & & & & \\
\hline GTA & & & 0,772 & & & \\
\hline OI/TA & & & & & 0,840 & \\
\hline $\mathrm{OI} / \mathrm{S}$ & & & & & 0,806 & \\
\hline SIGOI & & & & & & 0,991 \\
\hline
\end{tabular}

Fonte: banco de dados da Economática.

$\left(^{*}\right)$ Todas as demais cargas fatoriais foram inferiores a $0.40 \mathrm{e}$, portanto, suprimidas pelo software SPSS 8.0.

Como pode ser percebido a partir dos resultados da Tabela 8, a retirada da amostra do valor mínimo da proxy OI/S $(-914,827)$ referente à empresa Supergasbrás foi suficiente para tornar os resultados compatíveis com aqueles apresentados por México e Argentina ${ }^{(3)}$.

Considerando-se os efeitos que valores extremos poderiam ter sobre os resultados da Análise Fatorial dos demais países, em especial sobre o Chile, que apresentou comportamento em relação ao atributo lucratividade semelhante ao anteriormente apresentado pelo Brasil, decidiu-se empreender novamente a Análise Fatorial, retirando-se os valores extremos para todos os países (estes revelados pela Tabela 1 de estatísticas descritivas já apresentada). Os resultados, entretanto, não diferiram dos apresentados nas Tabelas 4 (México), 5 (Argentina) e 6 (Chile) $^{(4)}$.

Observadas as divergências em relação à primeira parte da metodologia (Modelo de Medida ou Análise Fatorial), passou-se à estimação das regressões lineares múltiplas. 


\section{Resultados da Regressão Linear Múltipla: Estimação e Avaliação dos Fatores Indutores do Endividamento}

Conforme exposto na Introdução deste trabalho, os resultados de Titman e Wessels (1988) para o mercado americano revelam que empresas que apresentam maior grau de singularidade e empresas mais lucrativas apresentam menor propensão ao endividamento, tanto de longo quanto de curto prazo, corroborando a teoria. Também empresas menores apresentaram maior propensão ao endividamento de curto prazo do que empresas maiores, provavelmente por não obterem taxas palatáveis na tentativa de obtenção de empréstimos mais longos.

Já Perobelli e Famá (2002), analisando o caso brasileiro, encontraram evidências de que empresas maiores, empresas lucrativas e empresas com maior potencial de crescimento apresentam menor propensão ao endividamento de curto prazo. Ressalta-se que essas relações não se alteraram significativamente, mesmo após a desconsideração dos valores extremos discutidos no item anterior, conforme pode ser percebido nas Tabelas 9 e 10, a seguir.

Tabela 9: Modelo para o Brasil

Estimativas dos Coeficientes da Regressão

(Estatística $t$ em Parênteses)

\begin{tabular}{|c|c|c|c|c|c|c|c|}
\hline \multirow{2}{*}{$\begin{array}{c}\text { Variáveis } \\
\text { dependentes } \\
\text { (endividamento) }\end{array}$} & \multicolumn{7}{|c|}{ Atributos } \\
\hline & $\begin{array}{c}\text { E1 } \\
\text { (Tamanho) }\end{array}$ & $\begin{array}{c}\text { E2 } \\
\text { (Colaterais) }\end{array}$ & $\begin{array}{c}\text { E3 } \\
\text { (Crescimento) }\end{array}$ & $\begin{array}{c}\text { E4 } \\
\text { (Singularidade) }\end{array}$ & $\begin{array}{c}\text { E5 } \\
\text { (Margem) }\end{array}$ & $\begin{array}{c}\text { E6 } \\
\text { (Lucratividade) }\end{array}$ & $\begin{array}{c}\text { E7 } \\
\text { (Volatilidade) }\end{array}$ \\
\hline $\begin{array}{l}\text { 1. LT/BVE } \\
(t)\end{array}$ & $\begin{array}{l}3.184 \\
(0.4) \\
\end{array}$ & $\begin{array}{l}1.820 \\
(0.2) \\
\end{array}$ & $\begin{array}{l}-3.921 \\
(-0.5) \\
\end{array}$ & $\begin{array}{c}12.189 \\
(1.6) \\
\end{array}$ & $\begin{array}{c}3.055 \\
(0.4) \\
\end{array}$ & $\begin{array}{c}-5.802 \\
(-0.7) \\
\end{array}$ & $\begin{array}{c}-1.769 \\
(-0.2) \\
\end{array}$ \\
\hline $\begin{array}{l}\text { 2. ST/BVE } \\
\qquad(t)\end{array}$ & $\begin{array}{c}-13.026^{*} \\
(-2.6)\end{array}$ & $\begin{array}{c}-2.464 \\
(0.4) \\
\end{array}$ & $\begin{array}{c}-9.924 * \\
(-2.0)\end{array}$ & $\begin{array}{l}5.628 \\
(1.1)\end{array}$ & $\begin{array}{l}3.971 \\
(0.8) \\
\end{array}$ & $\begin{array}{c}-17.301 * \\
(-3.5)\end{array}$ & $\begin{array}{c}-2.644 \\
(-0.5) \\
\end{array}$ \\
\hline
\end{tabular}

Fonte: Perobelli e Famá (2002).

* Significantes a $5 \%$.

Tabela 10: Modelo para o Brasil sem Outliers

Estimativas dos Coeficientes da Regressão

(Estatística $t$ em Parênteses)

\begin{tabular}{|c|c|c|c|c|c|c|}
\hline \multirow{2}{*}{$\begin{array}{c}\text { Variáveis } \\
\text { dependentes } \\
\text { (endividamento) }\end{array}$} & \multicolumn{6}{|c|}{ Atributos } \\
\hline & $\begin{array}{c}\text { E1 } \\
\text { (Tamanho) }\end{array}$ & $\begin{array}{c}\text { E2 } \\
\text { (Colaterais) }\end{array}$ & $\begin{array}{c}\text { E3 } \\
\text { (Crescimento) }\end{array}$ & $\begin{array}{c}\text { E4 } \\
\text { (Singularidade) }\end{array}$ & $\begin{array}{c}\text { E5 } \\
\text { (Lucratividade) }\end{array}$ & $\begin{array}{c}\text { E6 } \\
\text { (Volatilidade) }\end{array}$ \\
\hline $\begin{array}{l}\text { 1. LT/BVE } \\
(t)\end{array}$ & $\begin{array}{l}-2.718 \\
(-0.7) \\
\end{array}$ & $\begin{array}{c}1.746 \\
(0.5)\end{array}$ & $\begin{array}{r}1.386 \\
(0.4)\end{array}$ & $\begin{array}{r}-3.433 \\
(-0.9) \\
\end{array}$ & $\begin{array}{c}-6.746^{* *} \\
(-1.9) \\
\end{array}$ & $\begin{array}{r}-3.008 \\
(-0.8) \\
\end{array}$ \\
\hline $\begin{array}{l}\text { 2. ST/BVE } \\
(t)\end{array}$ & $\begin{array}{c}-10.919 * \\
(-2.2)\end{array}$ & $\begin{array}{c}3.586 \\
(0.7)\end{array}$ & $\begin{array}{c}-9.541^{*} \\
(-1.9)\end{array}$ & $\begin{array}{r}4.427 \\
(0.9)\end{array}$ & $\begin{array}{c}-19.561 * \\
(-3.9)\end{array}$ & $\begin{array}{l}-5.051 \\
(-1.0)\end{array}$ \\
\hline
\end{tabular}

Fonte: banco de dados da Economática.

* Significantes a $5 \%$; ** significantes a $10 \%$. 
No caso mexicano, como pode ser observado a partir da Tabela 11, foram encontradas relações negativas entre o grau de endividamento, tanto de curto prazo quanto de longo prazo, e os atributos/fatores lucratividade e crescimento dos ativos, indicando que, no México, empresas mais lucrativas ou em crescimento têm menos incentivo ao endividamento, corroborando a teoria. Por outro lado, a relação positiva, verificada entre o atributo/fator volatilidade, revela que, quanto maior a volatilidade dos resultados operacionais das empresas mexicanas, maior sua propensão ao endividamento. Tal relação poderia ser explicada pela ausência de outros mecanismos de financiamento neste mercado no período analisado, em especial para empresas com dificuldades operacionais, o que teria obrigado essas empresas a recorrer ao endividamento, mesmo a taxas abusivas.

\section{Tabela 11: Modelo para o México Estimativas dos Coeficientes da Regressão (Estatística $t$ em Parênteses)}

\begin{tabular}{|c|c|c|c|c|c|c|}
\hline \multirow{2}{*}{$\begin{array}{c}\text { Variáveis } \\
\text { dependentes } \\
\text { (endividamento) }\end{array}$} & \multicolumn{6}{|c|}{ Atributos } \\
\hline & $\begin{array}{c}\text { E1 } \\
\text { (Tamanho) }\end{array}$ & $\begin{array}{c}\text { E2 } \\
\text { (Lucratividade) }\end{array}$ & $\begin{array}{c}\text { E3 } \\
\text { (Outros } \\
\text { benefícios) }\end{array}$ & $\begin{array}{c}\mathrm{E} 4 \\
\text { (Crescimento) }\end{array}$ & $\begin{array}{c}\text { E5 } \\
\text { (Colaterais) }\end{array}$ & $\begin{array}{c}\text { E6 } \\
\text { (Volatilidade) }\end{array}$ \\
\hline $\begin{array}{l}\text { 1. LT/BVE } \\
(t)\end{array}$ & $\begin{array}{c}19.963^{* *} \\
(1.7) \\
\end{array}$ & $\begin{array}{c}-39.016 * \\
(-3.4) \\
\end{array}$ & $\begin{array}{c}-11.552 \\
(-1.0) \\
\end{array}$ & $\begin{array}{c}-25.190^{*} \\
(-2.2) \\
\end{array}$ & $\begin{array}{c}-12.663 \\
(-1.1) \\
\end{array}$ & $\begin{array}{c}50.820 * \\
(4.4) \\
\end{array}$ \\
\hline $\begin{array}{l}\text { 2. ST/BVE } \\
(t)\end{array}$ & $\begin{array}{c}13.940 \\
(0.9) \\
\end{array}$ & $\begin{array}{c}-58.719 * \\
(-4.0)\end{array}$ & $\begin{array}{c}-26.309 * * \\
(-1.8) \\
\end{array}$ & $\begin{array}{c}-33.558^{*} \\
(-2.3) \\
\end{array}$ & $\begin{array}{c}-21.304 \\
(-1.4)\end{array}$ & $\begin{array}{c}69.030 * \\
(4.7) \\
\end{array}$ \\
\hline
\end{tabular}

Fonte: banco de dados da Economática.

* Significantes a 5\%; ** significantes a $10 \%$.

Quanto ao endividamento de curto prazo, foi verificada uma relação negativa com o atributo/fator outros benefícios fiscais que não os gerados pelo endividamento, revelando que empresas que dispõem de outros benefícios fiscais têm menos incentivo ao endividamento de curto prazo.

Ainda quanto ao endividamento de longo prazo, foi identificada relação positiva entre essa variável e o atributo/fator tamanho, indicando que, quanto maior o porte da empresa mexicana, maior sua propensão ao endividamento de longo prazo.

No caso argentino, como pode ser observado a partir da Tabela 12, apenas foi encontrada relação negativa entre o grau de endividamento de curto prazo e o atributo/fator lucratividade, indicando que empresas mais lucrativas têm menos incentivo ao endividamento de curto prazo. 
Tabela 12: Modelo para a Argentina

\section{Estimativas dos Coeficientes da Regressão (Estatística $t$ em Parênteses)}

\begin{tabular}{|c|c|c|c|c|c|c|c|}
\hline \multirow{2}{*}{$\begin{array}{c}\text { Variáveis } \\
\text { dependentes } \\
\text { (endividamento) }\end{array}$} & \multicolumn{7}{|c|}{ Atributos } \\
\hline & $\begin{array}{c}\text { E1 } \\
\text { (Tamanho) }\end{array}$ & $\begin{array}{c}\text { E2 } \\
\text { (Crescimento) }\end{array}$ & $\begin{array}{c}\text { E3 } \\
\text { (Lucratividade) }\end{array}$ & $\begin{array}{c}\text { E4 } \\
\text { (Outros } \\
\text { benefícios) }\end{array}$ & $\begin{array}{c}\text { E5 } \\
\text { (Singularidade) }\end{array}$ & $\begin{array}{c}\text { E6 } \\
\text { (Volatilidade) }\end{array}$ & $\begin{array}{c}\text { E7 } \\
\text { (Colaterais) }\end{array}$ \\
\hline $\begin{array}{l}\text { 1. LT/BVE } \\
(t)\end{array}$ & $\begin{array}{l}1.502 \\
(0.2)\end{array}$ & $\begin{array}{c}2.463 \\
(0.3) \\
\end{array}$ & $\begin{array}{c}-3.176 \\
(-0.4) \\
\end{array}$ & $\begin{array}{c}10.868 \\
(1.5) \\
\end{array}$ & $\begin{array}{c}-2.112 \\
(-0.3)\end{array}$ & $\begin{array}{c}-3.391 \\
(-0.4)\end{array}$ & $\begin{array}{l}3.881 \\
(0.5) \\
\end{array}$ \\
\hline $\begin{array}{l}\text { 2. ST/BVE } \\
(t)\end{array}$ & $\begin{array}{l}0,379 \\
(0.0)\end{array}$ & $\begin{array}{l}-6.183 \\
(-0.7)\end{array}$ & $\begin{array}{c}-15.170 * * \\
(-1.8)\end{array}$ & $\begin{array}{c}13.262 \\
(1.6)\end{array}$ & $\begin{array}{l}9.903 \\
(1.2)\end{array}$ & $\begin{array}{c}-1.602 \\
(-0.1)\end{array}$ & $\begin{array}{l}-2.214 \\
(-0.2)\end{array}$ \\
\hline
\end{tabular}

Fonte: banco de dados da Economática.

* Significantes a $10 \%$.

No caso do Chile, como pode ser observado a partir da Tabela 13 e corroborando as teorias, foram encontradas relações positivas entre o atributo/fator estrutura dos ativos e o grau de endividamento de curto e longo prazo, indicando que quanto maior o volume de ativos suscetíveis de serem oferecidos como colaterais detidos pelas empresas chilenas, maior sua propensão ao endividamento.

Também foi encontrada relação positiva entre o atributo/fator tamanho e o grau de endividamento de longo prazo das empresas chilenas, indicando que, quanto maior o porte da empresa, maior sua propensão ao endividamento de longo prazo, conclusão reforçada pela relação negativa encontrada entre o fator e o endividamento de curto prazo.

Por fim, foi encontrada relação negativa entre o grau de endividamento de longo prazo e o atributo/fator lucratividade, indicando que, no Chile, empresas mais lucrativas têm menos incentivo ao endividamento de longo prazo.

\section{Tabela 13: Modelo para o Chile Estimativas dos Coeficientes da Regressão (Estatística $t$ em Parênteses)}

\begin{tabular}{|c|c|c|c|c|c|c|c|}
\hline \multirow{2}{*}{$\begin{array}{c}\text { Variáveis } \\
\text { dependentes } \\
\text { (endividamento) }\end{array}$} & \multicolumn{7}{|c|}{ Atributos (*) } \\
\hline & $\begin{array}{c}\text { E1 } \\
\text { (Tamanho) }\end{array}$ & $\begin{array}{c}\text { E2 } \\
\text { (Outros } \\
\text { benefícios) }\end{array}$ & $\begin{array}{c}\text { E3 } \\
\text { (Margem) }\end{array}$ & $\begin{array}{c}\mathrm{E} 4 \\
\text { (Colaterais) }\end{array}$ & $\begin{array}{c}\text { E5 } \\
\text { (Lucratividade) }\end{array}$ & $\begin{array}{c}\text { E6 } \\
\text { (Volatilidade) }\end{array}$ & $\begin{array}{c}\text { E7 } \\
\text { (Crescimento) }\end{array}$ \\
\hline $\begin{array}{l}\text { 1. LT/BVE } \\
(t)\end{array}$ & $\begin{array}{c}3.104 * \\
(2.3) \\
\end{array}$ & $\begin{array}{c}-0,775 \\
(-0.5) \\
\end{array}$ & $\begin{array}{c}-1.144 \\
(-0.8) \\
\end{array}$ & $\begin{array}{c}3.018^{*} \\
(2.3) \\
\end{array}$ & $\begin{array}{c}-2.379 * * \\
(-1.8) \\
\end{array}$ & $\begin{array}{r}-0,801 \\
(-0.6) \\
\end{array}$ & $\begin{array}{l}1.849 \\
(1.4) \\
\end{array}$ \\
\hline $\begin{array}{l}\text { 2. ST/BVE } \\
\qquad(t)\end{array}$ & $\begin{array}{c}-1.831 * \\
(-2.2)\end{array}$ & $\begin{array}{c}-0,380 \\
(-0.4) \\
\end{array}$ & $\begin{array}{c}-0,063 \\
(-0.0)\end{array}$ & $\begin{array}{c}1.615^{*} \\
(1.9)\end{array}$ & $\begin{array}{c}-0,742 \\
(-0.9)\end{array}$ & $\begin{array}{l}-0,121 \\
(-0.1)\end{array}$ & $\begin{array}{c}-1.167 \\
(-1.4) \\
\end{array}$ \\
\hline
\end{tabular}

Fonte: banco de dados da Economática.

* Significantes a $5 \%$; ** significantes a $10 \%$. 


\section{Considerações Finais}

Os resultados obtidos neste trabalho e a sua comparação com outros estudos desenvolvidos anteriormente para os mercados americano e brasileiro, apontam na direção de que a escolha da estrutura de capital pelas empresas em diferentes cenários seja antes influenciada por atributos teóricos próprios dessas empresas do que uma escolha única.

A despeito da escolha em cada país ser influenciada por diferentes fatores, algumas semelhanças interessantes, e suas potenciais implicações para o mercado de ações e para o mercado de bônus corporativos (dívida), merecem ser destacadas.

Em primeiro lugar, todos os casos apresentados parecem indicar a direção da pecking order theory de Myers (1984), ao revelar que empresas que obtêm mais lucros optam menos pelo endividamento. Endossando essa ordenação, tomese a Hipótese de Sinalização de Ross (1977) que sugere que, implícito na hipótese de irrelevância de Modigliani e Miller (1958) está a premissa de que os investidores conhecem com certeza a distribuição dos fluxos operacionais futuros a serem gerados pela empresa, quando estes, na verdade, são aleatórios. Assumindo-se que gerentes e acionistas detêm informações mais precisas sobre os projetos a serem aceitos pela empresa que o mercado, caso os acionistas existentes aceitem financiar um novo projeto, via lucros retidos, por exemplo, isso pode ser interpretado pelo mercado como sinal positivo: a utilização de lucros retidos pela empresa revelará que o projeto assumido é viável, o que provocará a elevação do valor de mercado da empresa.

Empresas lucrativas, portanto, teriam menos incentivo para utilizar tanto o mercado de ações como o mercado de dívidas para se financiarem.

Em segundo lugar, os resultados revelam que empresas com alto potencial de crescimento, em setores ainda não consolidados, caso brasileiro e mexicano, e empresas que detêm alto volume de ativos intangíveis ou comercializam produtos altamente especializados, caso americano e chileno, enfrentariam custos menores, promovendo a emissão de ações, em detrimento da emissão de dívida. Tais conclusões encontram fundamentação na teoria de Expropriação de Riqueza dos Credores pelos Acionistas. McConnell e Servaes (1995) afirmaram que, para empresas com baixo potencial de crescimento, onde o número de projetos disponíveis é pequeno, limitando a criatividade dos acionistas, o valor da empresa aumenta com o nível de endividamento. Já para empresas com alto potencial de crescimento, potenciais expropriadoras, seu valor é reduzido pela contratação de 
dívida, o que explicaria os baixos níveis de endividamento encontrados nessas empresas.

Empresas em crescimento, portanto, seriam potenciais usuárias do mercado de ações, ao tentar obter financiamento para novos projetos.

A última relação relevante diz respeito ao tamanho das empresas. Os resultados encontrados em todos os mercados indicam que, enquanto empresas maiores privilegiam o endividamento de longo prazo, empresas menores utilizam mais o endividamento de curto prazo, provavelmente por não obterem taxas atrativas no primeiro mercado.

\section{Notas}

\footnotetext{
${ }^{1}$ Para um entendimento mais completo dos custos de agência relacionados à obtenção de dívidas, recomendam-se os textos de Jensen (1986), Stulz (1990) e McConnell e Servaes (1995).

${ }^{2}$ Para uma análise mais detalhada do método, ver Perobelli e Famá (2002).

${ }^{3}$ Como será explicitado adiante, os resultados da regressão para o Brasil não se alteram significativamente, desconsiderando-se esses valores extremos.

${ }^{4}$ Uma nota em relação ao valor mínimo da proxy OI/S para o Chile (-3.882,6) merece ser apresentada. À primeira vista, a desconsideração desse valor na análise poderia ter o mesmo efeito que a retirada do valor mínimo extremo no caso brasileiro. Entretanto é importante notar que, no caso chileno, o percentual da margem convertido em lucratividade é mais baixo que o apresentado pelos demais países, mesmo sendo a medida utilizada (mediana) não influenciada por valores extremos; portanto a retirada desse valor não produziu para o Chile os mesmos resultados produzidos para o Brasil.
}

\section{ReferênCias Bibliográficas}

ALLEN, M.

Capital structure determinants in real estate limits partnerships.

Financial Review, v. 30, n. 3, Aug. 1995.

\section{BALAKRISHNAN, S.;} FOX, I.

Asset specificity, firm heterogeneity and capital structure. Strategic

Management Journal, v. 14, 1993.

BLACK, F;

SCHOLES, $M$.

The pricing of options and corporate liabilities. Journal of Political Economy, v. 81, p. 637659, 1973. 
BRADLEY, M.;

JARREL, G.;

KIM, $\mathrm{H}$.

On the existence of an optimal capital structure: theory and evidence. The Journal of Finance, v. 39, n. 3, July 1984.

DEANGELO, H.;

MASULIS, R.

Optimal capital structure under corporate and personal taxation. Journal of Financial Economics, v. 8, Mar. 1980.

\section{DURAND, D}

Cost of debt and equity funds for business: trends and problems of measurement. In: CONFERENCE ON RESEARCH ON BUSINESS FINANCE, 1952, New York. Proceedings... New York: [s.n.], 1952.

The cost of capital, corporate finance and the theory of investment: comment. American Economic Review, v. 49, n. 4, p. 639-655, Sept. 1959.

EID JR., W.

Custo e estrutura de capital: o comportamento das empresas brasileiras. Revista de Administração de Empresas, v. 36, n. 4, 1996.
FERRI, M.;

JONES, W.

Determinants of financial structure: a new methodological approach. The Journal of Finance, v. 34, n. 3, June 1979.

JENSEN, M.

Agency costs of free cash flow, corporate finance and takeover. American Economic Review, v. 76, 1986.

JOHNSON, R. A.; WICHERN, D. W.

Applied multivariate statistical analysis. 3. ed. New Jersey: Prentice-Hall, 1992.

JORGE, S.;

ARMADA, M. J.

Factores determinantes do endividamento: uma análise em painel. In: ENCONTRO ANUAL DA ANPAD, 23., 1999, Foz do Iguaçu. Anais... Foz do Iguaçu: ANPAD, 1999. 1 CDROM.

KAYO, E.; FAMÁ, R.

Agency cost and the Brazilian bankruptcy law: assumptions on the reduction of conflicts of interest. Journal of Emerging Markets, v. 2, n. 3, Fall-Winter 1997. 
LUMBY, S.

Investment appraisal and financing decisions: a first course in financial management. 4. ed. [S.l.]: Chapman \& Hall, 1991.

MCCONNELL, J.;

SERVAES, $\mathrm{H}$.

Equity ownership and the two faces of debt. Journal of Financial Economics, v. 39, p.131-157, 1995.

MILLER, M.

Debt and taxes. Journal of Finance, p. 261-275, 1977.

MODIGLIANI, F.;

MILLER, $M$.

The cost of capital, corporation finance, and the theory of investment. American

Economic Review, v. 48, n. 3, p. 261-297, June 1958.

The cost of capital, corporation finance, and the theory of investment: reply. American Economic Review, v. 49, n. 4, p. 655-669, Sept. 1959.

Corporate income taxes and the cost of capital: a correction. American Economic Review, v. 53, n. 3, p. 433-443, June 1963.

MYERS, S.

The capital structure puzzle. Journal of Finance, p. 575-592, July 1984.
MYERS, S.;

MAJLUF, N.

Corporate financing and investment decisions when firms have information that investors do not have. Journal of Financial Economics, v. 13, 1984.

PEROBELLI, F.;

FAMÁ, R.

Determinantes da estrutura de capital: aplicação a empresas de capital aberto brasileiras. Revista de Administração, v. 37, n. 3, jul.-set. 2002.

RAJAN, R.;

ZINGALES, L.

What do we know about capital structure? Some evidence from international data. Journal of Finance, v. 50, n. 5, Dec. 1995.

REMMERS, L. et al.

Industry and size as debt ratio determinants in manufacturing internationally. Financial Management, Summer 1974.

ROSS, S.

The determination of financial structure: the incentive signaling approach. Bell Journal of Economics, p. 23-40, Spring 1977.

SCOTT, F.;

MARTIN, J.

Industry influence on financial structure.

Financial

Management, Spring 1975. 
SOARES, K.;

PROCIANOY, J.

$O$ perfil de endividamento das empresas negociadas na Bolsa de

Valores de São Paulo após o Plano Real. In: ENCONTRO ANUAL DA ANPAD, 24., 2000, Florianópolis.

Anais...

Florianópolis: ANPAD, 2000. 1 CD-ROM.

STONEHILL, A. et al.

Financial goals and debt ratio determinants: a survey of practice in five countries. Financial Management, Autumn 1975.

STULZ, R.

Managerial discretion and optimal financing policies. Journal of Financial Economics, v. 26, 1990.
THIES, C.;

KLOCK, M.

Determinants of capital structure. Review of Financial Economics, v. 2, Summer 1992.

TITMAN, S.; WESSELS, R.

The determinants of capital structure choice. Journal of Finance, v. 48, n. 3, June 1988.

TOY, N. et al.

A comparative international study of growth, profitability and risk as determinants of corporate debt ratios in the manufacturing sector. Journal of Finance and Quantitative Analysis, Nov. 1974. 